\title{
Rancang Bangun Aplikasi Mobile Learning Anak Sekolah Minggu dengan Teknologi Augmented Reality Berbasis Android
}

\author{
Sheila Claudy Riady ${ }^{1)}$, Steven Sentinuwo ${ }^{2)}$, Stanley Karouw ${ }^{3)}$ \\ 1,2,3 Program Studi Teknik Informatika, Fakultas Teknik, Universitas Sam Ratulangi \\ E-mail : 120216006@ student.unsrat.ac.id ${ }^{1)}$,steven@ unsrat.ac.id ${ }^{2)}$ stanley.karouw@ unsrat.ac.id ${ }^{3)}$
}

\begin{abstract}
Abstrak - Sekolah Minggu merupakan kegiatan Gereja untuk menjangkau dan membawa setiap orang kepada Tuhan Yesus serta mengajarkan Alkitab untuk mengarahkan kehidupan agar dapat semakin serupa dengan Kristus. Masalah yang dihadapi oleh Guru Sekolah Minggu (GSM) dalam menyajikan cerita adalah terkadang kekurangan alat peraga. Karena itu dibuatlah sebuah aplikasi mobile learning ( $m$ learning) yang merupakan sebuah media pembelajaran dengan menggunakan teknologi informasi dan komunikasi untuk membantu proses menyajikan cerita Alkitab. Agar dapat diakses dengan mudah maka aplikasi dibuat berbasis android dan memanfaatkan teknologi Augmented Reality (AR) yang memungkinkan kita untuk menambahkan visualisasi berupa animasi tiga dimensi dengan bantuan image target yang ada sehingga aplikasi dapat dijadikan sebagai alat peraga digital menarik, menyenangkan, mudah diterima dan dipahami untuk anak-anak. Metodologi yang digunakan dalam penelitian ini adalah metodologi Rapid Application Development (RAD).

Penelitian ini menghasilkan sebuah aplikasi Marble (Magic Augmented Reality Bible) yang dapat membantu Guru Sekolah Minggu dalam memperkenalkan hewan ciptaan Tuhan sesuai dengan pengelompokkan hewan tersebut yang tertulis dalam Kitab Kejadian 1 :20-25 serta membantu Anak Sekolah Minggu dalam mengenal hewan yang telah diciptakan Tuhan.
\end{abstract}

Kata Kunci : Android, Augmented Reality, Marble, M-learning, Rapid Application Development

\section{PENDAhuluan}

Guru-guru sekolah minggu ditantang untuk semakin kreatif dan inovatif dalam mengajarkan cerita Alkitab agar anak-anak sekolah minggu tertarik untuk mendengarkan cerita Alkitab. Bahkan untuk mempermudah anak-anak sekolah minggu dalam mengerti cerita Alkitab sebaiknya guru-guru sekolah minggu memberikan contoh-contoh yang berkaitan dengan kehidupan sehari-hari. Pengenalan hewan dapat merangsang otak anak untuk berimajinasi dan melatih kreativitas (Rosjad, 2014). Apalagi pengenalan hewan diambil dari cerita Alkitab karena dalam Alkitab terdapat juga cerita yang berkaitan dengan hewan. Anak-anak akan lebih mudah memahami jika Allah memang benar-benar menciptakan makhluk hidup (terlebih khusus hewan). Karena saat ini untuk alat peraga digital yang mengajarkan anak sekolah minggu tentang cerita Alkitab masih kurang. Selama ini pengenalan hewan kepada anak masih banyak yang menggunakan buku atau kertas poster. Hingga peneliti berkeinginan menggunakan teknologi Augmented Reality (AR). AR merupakan upaya untuk menggabungkan dunia nyata dan dunia virtual yang dibuat melalui komputer sehingga jarak antara keduanya akan sangat tipis. Teknologi AR dapat membantu proses pengenalan hewan dengan cara yang menarik, menyenangkan, mudah diterima dan dipahami. Dengan teknologi ini hewan seakan-akan nyata karena dalam bentuk tiga dimensi (3D). AR bahkan bisa dengan mudah diakses dengan menggunakan perangkat Android misalnya smartphone ataupun tablet.

Dari hasil pembahasan diatas maka peneliti akan mengembangkan teknologi AR untuk pengenalan hewan berbasis android yang nantinya dapat mempermudah guru sekolah minggu sebagai pengajar dalam mengajarkan cerita dan anak-anak dalam mendengar cerita Alkitab (Cerita Penciptaan hewan) yang terdapat dalam Kitab Kejadian 1:2025 .

\section{LANDASAN TEORI}

\section{A. Landasan Ayat Alkitab}

Dalam pembuatan aplikasi, peneliti membuat pengelompokkan hewan air, burung, binatang liar, binatang ternak dan binatang melata sesuai dengan yang tertulis dalam Alkitab (Kejadian 1: 20 - 25).

"Berfirmanlah Allah : "Hendaklah dalam air berkeriapan makhluk yang hidup, dan hendaklah burung berterbangan diatas bumi melintasi cakrawala." Maka Allah menciptakan binatang-binatang laut yang besar dan segala jenis makhluk hidup yang bergerak, yang berkeriapan dalam air, dan segala 
jenis burung yang bersayap. Allah melihat bahwa semuanya itu baik. Lalu Allah memberkati semuanya itu, firman-Nya : "Berkembangbiaklah dan bertambah banyaklah serta penuhilah air dalam laut, dan hendaklah burung-burung di bumi bertambah banyak." Jadilah petang dan jadilah pagi, itulah hari kelima. Berfirmanlah Allah : "Hendaklah bumi mengeluarkan segala jenis makhluk yang hidup, ternak dan binatang melata dan segala jenis binatang liar." Dan jadilah demikian. Allah menjadikan segala jenis binatang liar dan segala jenis ternak dan segala jenis binatang melata di muka bumi. Allah melihat bahwa semuanya itu baik."

\section{B. Sekolah Minggu}

Sekolah Minggu merupakan kegiatan gereja untuk menjangkau dan membawa setiap orang kepada Tuhan Yesus serta mengajarkan Alkitab untuk mengubah kehidupan mereka menjadi murid Tuhan yang penuh pengharapan (Sutanto, 2008).

Sekolah Minggu merupakan kegiatan belajar bagi anakanak yang didalamnya terdapat aktivitas belajar mengajar. Kegiatan yang dilakukan umumunya bernyanyi bersama, berdoa, membaca Alkitab dan mendengarkan cerita Alkitab yang dibawakan oleh guru sekolah minggu. Penyajian cerita biasa disertai dengan gambar-gambar yang mendukung cerita. Gambar-gambar sedianya merupakan alat peraga yang membantu anak dalam memahami akan sesuatu. (Mamangkey et al. 2013).

Sekolah minggu sama pentingnya dengan sekolah formal yang mengajarkan pengetahuan, keterampilan, dan perilaku. Pelajaran yang diajarkan dalam sekolah minggu termasuk di dalamnya menghafal ayat-ayat tertentu dan lagu-lagu rohani.

Peran dan fungsi sekolah minggu adalah 2 aspek yang saling berkaitan. Aspek-aspek tersebut antara lain pusat pendidikan non-formal, ujung tombak pekerjaan penginjilan, alat penjangkau dan penyalur berkat.

\section{Mobile Learning (M-Learning)}

Mobile Learning dapat diartikan sebagai perpotongan komputasi mobile dan e-learning dimana sumber daya harus dapat di akses di manapun, kaya interaksi, dukungan yang kuat untuk pembelajaran efektif, dan penilaian berbasis kinerja.

Berdasarkan definisi diatas m-learning merupakan pembelajaran yang memanfaatkan teknologi informasi dan komunikasi. M-learning membuat materi ajar yang telah disediakan dapat diakses setiap saat dan menarik untuk dipelajari. Mobile learning dapat dikelompokkan dalam beberapa klasifikasi berdasarkan indikator-indikator sebagai berikut :

a) Jenis mobile device yang didukung: notebook, Tablet PC, PDA, smartphone, atau telepon seluler.

b) Jenis komunikasi nirkabel yang digunakan untuk mengakses bahan pembelajaran dan informasi administratif: GPRS, GSM, IEEE 802.11, Bluetooth, IrDA.

c) Dukungan edukasi secara sinkron dan/atau asinkron, apakah pengguna dapat berkomunikasi secara sinkron (chat, komunikasi suara) atau asinkron (email, SMS) dengan pengajar.

d) Dukungan terhadap standar e-learning. e) Ketersediaan terhadap koneksi internet yang permanen antara sistem mobile learning dengan pengguna.

f) Lokasi pengguna.

g) Akses ke materi pembelajaran dan/atau layanan administratif

\section{Augmented Reality (AR)}

Augmented Reality merupakan teknologi yang menggabungkan benda maya (dua dimensi atau tiga dimensi) ke dalam sebuah lingkungan nyata lalu memproyeksikan benda-benda maya tersebut dalam waktu nyata (real time). AR dapat juga didefinisikan sebagai teknologi yang mampu menggabungkan objek maya dalam dua dimensi (2D) dan tiga dimensi (3D) ke dalam sebuah lingkungan nyata, kemudian memproyeksikan objek-objek tersebut secara real time.

Augmented Reality (AR) mengabungkan dunia nyata dengan dunia virtual. Augmented Reality (AR) hanya menambahkan serta melengkapi kenyataan berbeda dengan realitas maya yang menggantikan kenyataan sepenuhnya. Terdapat tiga karakteristik dari sistem AR menurut Azuma,yaitu :

1. Mengkombinasikan kenyataan dan objek virtual dalam lingkungan nyata 3D (real environment)

2. Berjalan secara interaktif dan waktu yang nyata (real time)

3. Terdapat integrasi antar benda dalam tiga dimensi, yaitu benda maya terintegrasi dalam dunia nyata.

Metode dalam AR bisa dibagi menjadi dua, yaitu Marker Based Tracking dan Markerless AR.

\section{Marker Augmented Reality (Marker Based Tracking)}

AR penggunaan marker biasanya berupa ilustrasi hitam putih persegi dengan batas hitam tebal dan latar belakang putih. Saat akan dipindai (scan) komputer akan mengenali posisi dan orientasi marker dan menciptakan dunia virtual 3D yaitu titik $(0,0,0)$ dan tiga sumbu yaitu X, Y, dan Z.

\section{Markerless Augmented Reality}

Metode AR yang banyak digunakan saat ini adalah metode Markerless atau tanpa marker. Dengan metode ini tidak perlu ada marker hitam putih.

Terdapat beberapa macam teknik Markerless AR ini, antara lain :

a. Face Tracking : Dengan teknologi yang semakin maju membuat saat ini komputerpun dapat mengenali wajah manusia secara umum dengan mengenali posisi panca indera manusia (mata, hidung, mulut).

b. $3 D$ Object Tracking : Dengan teknologi 3D objek tracking perangkat dapat mengenali semua bentuk benda yang ada disekitar kita seperti mobil, meja, kursi, dan lain-lain.

c. Motion Tracking : Dengan teknologi Motion Tracking perangkat dapat menangkap gerakan. Teknologi telah digunakan dalam pembuatan filmfilm yang mencoba menstimulasikan gerakan.

d. GPS Based Tracking : Dengan teknologi Based Tracking perangkat dapat mengambil data dari GPS dan kompas dan menampilkannya dalam bentuk arah 
yang kita inginkan secara real time. Teknik ini banyak dikembangkan pada aplikasi pada smart phone (iPhone dan Android).

\section{E. Android}

Android adalah sebuah sistem operasi berbasis Linux yang digunakan untuk perangkat mobile seperti telepon pintar (smartphone) dan komputer tablet. Android mencakup sistem operasi, middleware, dan aplikasi yang menyediakan platform terbuka untuk bagi para pengembang untuk menciptakan aplikasi mereka.

Android didirikan tahun 2003 di California oleh Andy Rubin (pendiri Danger), Rich Miner (pendiri Wildfire Communications,Inc.), Nick Sears dan Christ White (kepala desain dan pengembangan antarmuka WebTV).

Tujuan awal pengembangan android yaitu mengembangkan sebuah sistem operasi yang canggih dan diperuntukkan bagi kamera digital, namun disadari bahwa pasar untuk perangkat itu tidak cukup besar. Pengembangan Android dialihkan bagi pasar smartphone.

\section{F. Multimedia}

Multimedia dapat diartikan sebagai perpaduan dari berbagai media yang terdiri dari teks, grafis, gambar diam, animasi, suara, dan video untuk menyampaikan pesan kepada publik. (Warsita, 2008)

Sementara itu, menurut Warsita komputer mempunyai kemampuan untuk menyimpan, mengolah, dan menyajikan data secara cepat. Jenis multimedia dapat dibedakan menjadi dua, yaitu:

- Multimedia linier, suatu multimedia yang tidak dilengkapi dengan alat pengontrol apapun yang dapat dioperasikan oleh pengguna.

- Multimedia interaktif, kombinasi dari berbagai media yang dikemas secara terpadu dan interaktif untuk menyajikan pesan pembelajaran tertentu.

\section{G. Tools yang Digunakan}

\section{Unity 3D}

Unity 3D adalah sebuah game engine yang berbasis crossplatform. Unity dapat digunakan untuk membuat sebuah game yang bisa digunakan pada perangkat komputer, Android, iPhone, PS3, dan X-Box. Unity adalah sebuah sebuah tool yang terintegrasi untuk membuat game, arsitektur bangunan dan simulasi. Unity bisa untuk games PC dan games online. Games online memerlukan sebuah plugin, yaitu Unity Web Player sama halnya dengan Flash Player pada browser.

\section{Vuforia SDK}

Vuforia SDK adalah Software Development Kit berbasis AR yang menggunakan layar perangkat mobile sebagai "lensa ajaib" atau kaca untuk melihat kedalam dunia Augmented dimana dunia nyata dan virtual muncul berdampingan. Aplikasi ini membuat preview kamera secara langsung pada layar smartphone untuk mewakili pandangan dari dunia fisik. Objek 3D akan Nampak secara langsung dilayar smartphone, sehingga akan terlihat Objek 3D berada di dalam dunia nyata.

\section{Wafosaur}

Wavosaur merupakan perangkat lunak sound editor, audio editor, wav editor gratis untuk mengedit, memproses, dan merekam suara, wav dan mp3 file.

\section{H. Metodologi Pengembangan Sistem Perangkat Lunak}

Rapid Application Development (RAD) merupakan salah satu metode pengembangan suatu sistem informasi dengan waktu yang relatif singkat. RAD adalah sebuah strategi pengembangan sistem dimana menekan kecepatan pengembangan melalui keterlibatan user ekstensif dalam kecepatan, iterative (berulang) dan incrumental construction dari serangkaian fungsi dari prototype sebuah sistem yang pada akhirnya akan mengalami perubahan secara bertahap menuju sistem akhir. Tahapan dari RAD dapat dilihat pada gambar 1.

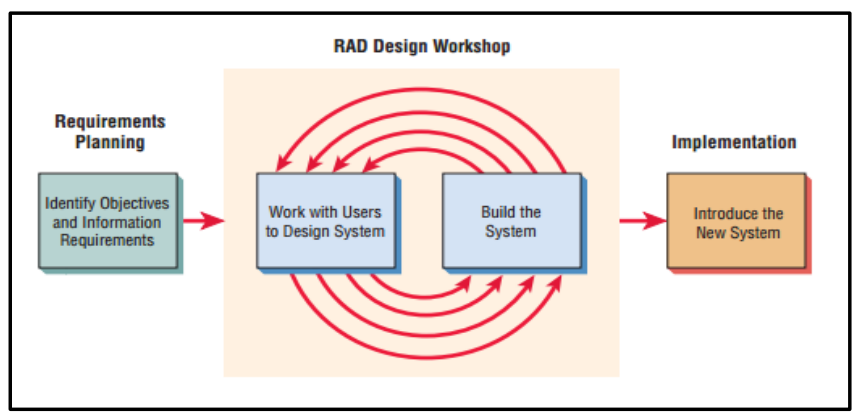

Gambar 1. Tahapan RAD

(Kendall, J.E. \& Kendall, K.E,2010)

\section{METODOLOGI PENELITIAN}

\section{A. Identifikasi Masalah}

Pada tahap ini peneliti mengidentifikasi masalah yang ada dengan melakukan observasi, wawancara dan membaca referensi.

B. Analisis Persyaratan

Tahap ini bertujuan untuk mengidentifikasikan kebutuhan pengguna, spesifikasi sistem yang telah dilakukan melalui observasi dan pengumpulan data sebelumnya, sehingga aplikasi yang akan dibuat akan sesuai dengan yang dibutuhkan oleh pengguna.

Pada tahapan ini juga peneliti melakukan pengumpulan data/persyaratan dengan dua metode, yaitu penggumpulan data primer dan pengumpulan data sekunder.

C. Analisis Modeling

Tahap ini bertujuan untuk menganalisis sistem yang sedang berjalan dari semua kegiatan yang terjadi pada sistem. Aktivitas yang akan dilakukan adalah identifikasi pelaku dan menganalisis proses dan kinerja sistem.

D. Desain Modeling

Tahap ini bertujuan untuk melakukan perancangan sistem melalui analisis kebutuhan dan persyaratan dari pengguna yang telah dilakukan sebelumnya. Aktivitas yang akan dilakukan pada fase ini ada dua yaitu: Memodelkan diagram use case dan Perancangan antar muka.

E. Konstruksi

Tahap ini akan menunjukan platform, hardware, 
software, batasan implementasi dan pengujian aplikasi yang telah dibangun apakah sudah sesuai dengan kebutuhan user dan spesifikasi persyaratan yang sebelumnya telah dianalisis. Aktivitas yang dilakukan yaitu, lingkungan implementasi, membuat algoritma, melakukan pemrograman, implementasi antarmuka dan pengujian.

Pada tahapan melakukan pemrograman peneliti membuat nama aplikasi, yaitu aplikasi "Marble" dengan alasan aplikasi yang dihasilkan nantinya merupakan aplikasi dengan teknologi Augmented Reality (AR). Teknologi AR dapat menggabungkan benda maya (dua dimensi atau tiga dimensi) ke dalam sebuah lingkungan nyata lalu memproyeksikan benda-benda maya tersebut dalam waktu nyata. Dan aplikasi juga aplikasi dibuat berdasarkan cerita Alkitab. Jadi peneliti memilih untuk menggunakan nama "Marble" sebagai nama aplikasi. Marble merupakan singkatan dari "Magic Augmented Reality Bible".

Pada tahap konstruksi ini, alat dan bahan yang digunakan sebagai berikut :

1. Laptop yang digunakan adalah Laptop Asus X450JN dengan spesifikasi

- Processor Intel Core i7

- $\quad$ Installed memory (RAM) 8 GB

- Operating System Windows 8.1 Pro 64 bit

2. Printer yang digunakan adalah printer Canon MP276 dengan spesifikasi

- $\quad$ Printing Method InkJet

- Max. Resolution 4800

- Effective Print Resolution 4800 x 1200dpi (max.)

- Print Speed Black ppm 8.4ipm

- $\quad$ Print Speed Color ppm 4.8 ipm

3. Smartphone yang digunakan adalah smartphone Android Galaxy Mega 2 .

4. Software Unity3D yang digunakan adalah Unity versi 5.2.0. Unity dipakai dalam mengatur visualisasi objek 3D, antarmuka aplikasi dan membuat fitur-fitur aplikasi melalui MonoDevelop (mengetikan source code program)

5. Software Vuforia SDK yang digunakan adalah versi 6.0.117. Vuforia dipakai dalam proses pembuatan AR aplikasi.

6. Software photoshop yang digunakan adalah photoshop CS6. Photoshop membantu peneliti dalam proses perancangan antarmuka (interface) aplikasi.

7. Software canva digunakan dalam proses perancangan antarmuka (interface) aplikasi.

8. Software wavosaur yang merupakan software untuk pengolahan suara. Digunakan dalam pengeditan suara aplikasi Marble dan suara objek hewan.

9. Software StarUML digunakan dalam pembuatan diagram UML.

10. Software Microsoft word 2007 digunakan dalam pembuatan dokumen.

11. Alat tulis menulis yang digunakan berupa pensil, pulpen, penghapus, kertas, dan sebagainya.
Sebelum pembuatan aplikasi, peneliti membuat multimedia storyboard. Gambar 2 merupakan salah satu contoh dari storyboard aplikasi Marble.

\begin{tabular}{|l|l|}
\hline Multimedia Story Board \\
\hline Project : Marble \\
\hline $\begin{array}{c}\text { Tombol } \\
\text { Rotasi }\end{array}$ \\
\hline $\begin{array}{c}\text { Tombol } \\
\text { Stop }\end{array}$
\end{tabular}

Gambar 2. Contoh multimedia story board aplikasi Marble

Proses awal dari pembuatan aplikasi Markerless Augmented Reality menggunakan software Unity adalah membuat image target yang nantinya akan di upload melalui vuforia (Software Development Kit berbasis AR). Gambar 3 merupakan tampilan license key yang telah dibuat melalui vuforia.

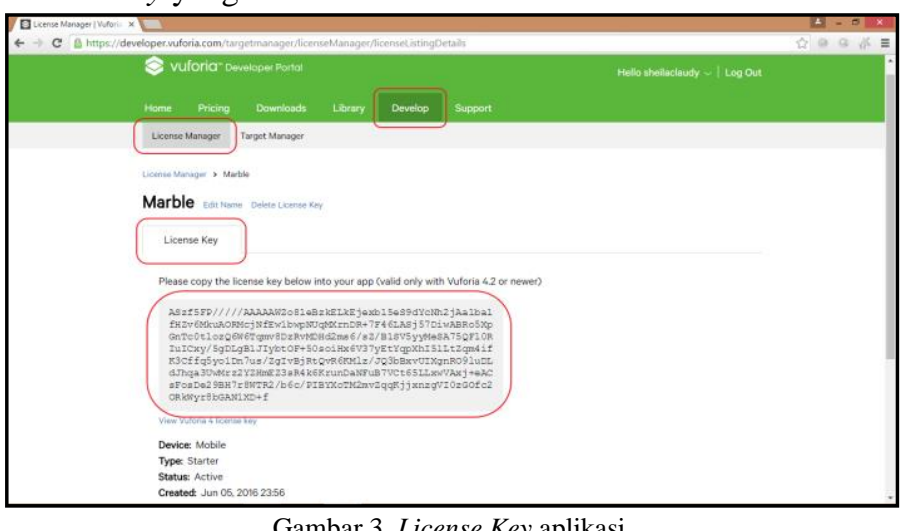

Gambar 3. License Key aplikasi

Setelah lisensi aplikasi telah dibuat, upload image target melalui vuforia dan download database. Gambar 4 merupakan tampilan saat database image target didownload. 


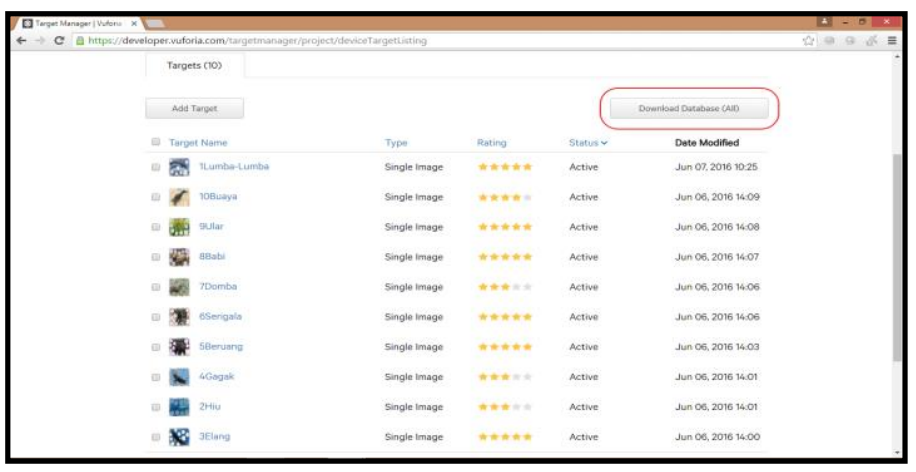

Gambar 4. Database image target

Setelah database image target berhasil di download. Buka Unity dan buat proyek aplikasi Marble. Hapus main camera pada hierarchy dan import database image target serta vuforia dalam Unity. Proses import bisa dengan memilih menu Assets > import package > custom package. Bisa juga dengan cara drag and drop langsung ke menu assets. Dapat dilihat pada gambar 5 .

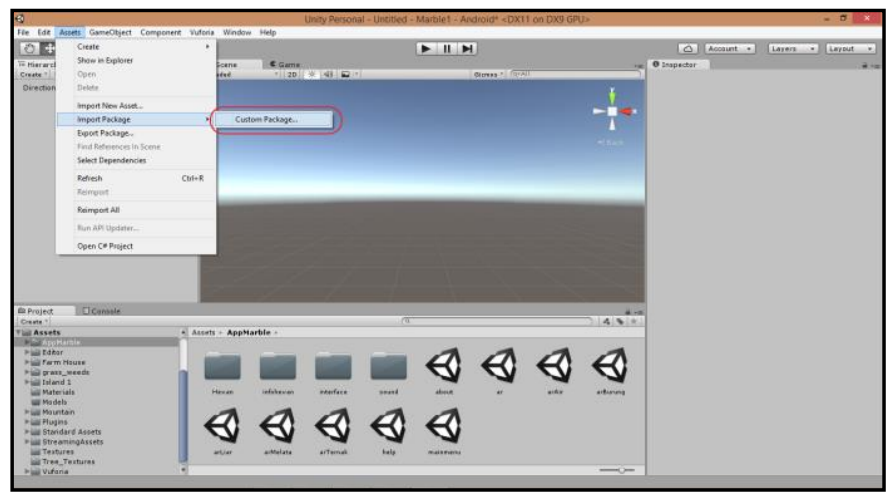

Gambar 5. Import vuforia ke unity

Pilih Database yang telah di import dan image target. Pada tahap ini peneliti memilih database Marble dan image target hewan sesuai dengan jenisya. Setelah selesai, peneliti mulai memasukan dan mengatur objek 3 dimensi tepat diatas image target.

Agar lebih menarik, dibuat slide show informasi hewan dengan mengetikkan source code. Dapat dilihat pada gambar 6.

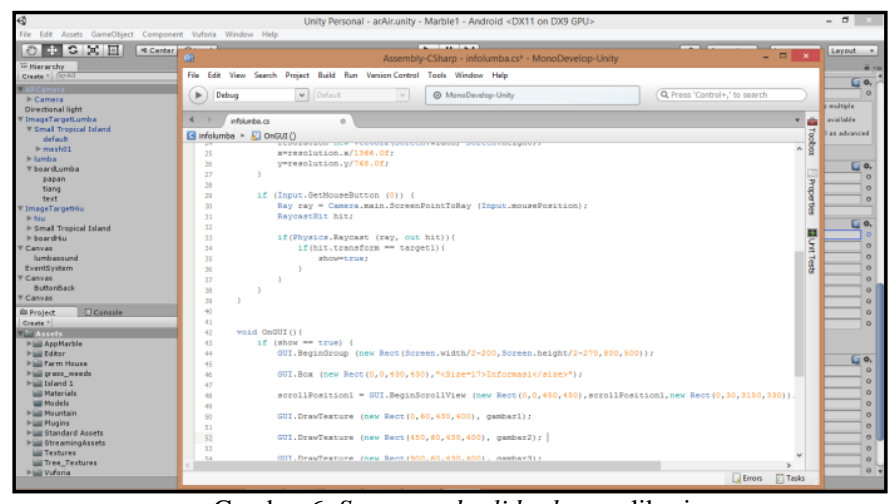

Gambar 6. Source code slide show aplikasi

Peneliti juga menambahkan tombol-tombol (button) untuk mempermudah interaksi antara user dengan aplikasi. Setelah semua button berhasil diimport ke unity, source code semua button mulai dibuat melalui mono develop unity. Gambar 7 merupakan tampilan dari button aplikasi.

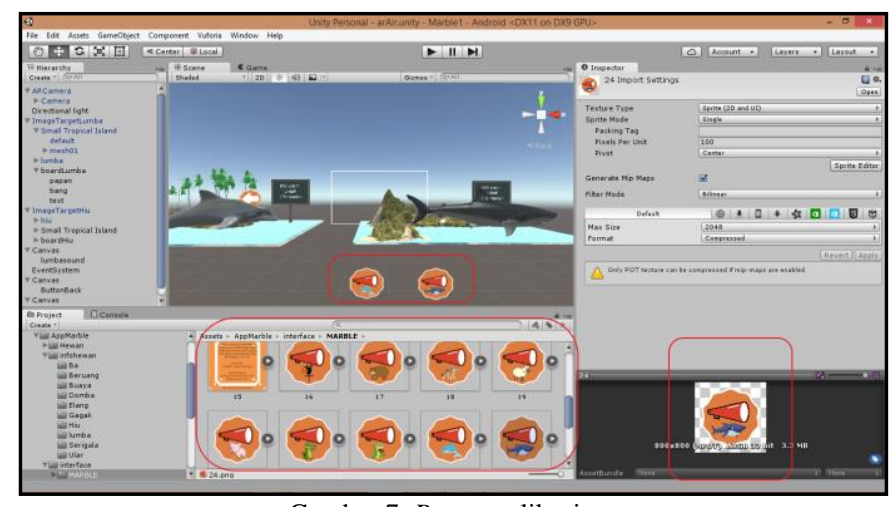

Gambar 7. Button aplikasi

Saat semua scene (untuk menampilkan hewan) berhasil dibuat, peneliti mulai membuat interface aplikasi. Gambar 8 merupakan contoh tampilan salah satu menu aplikasi.

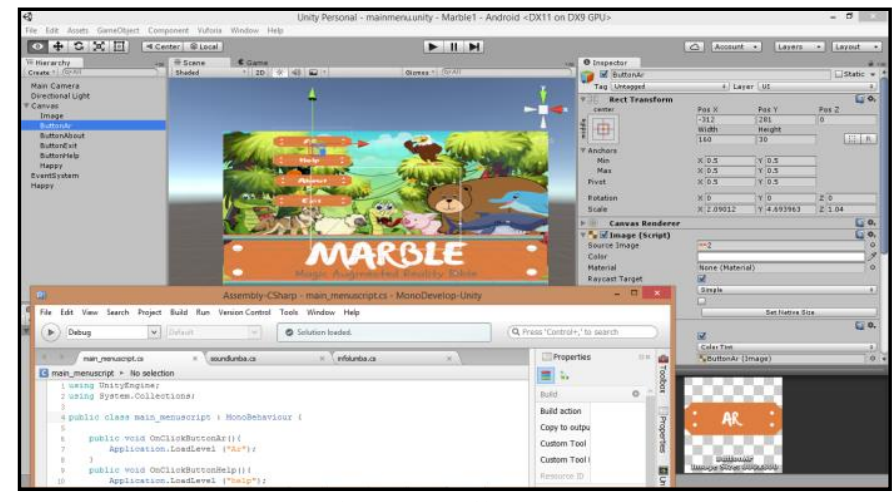

Gambar 8. Tampilan Interface

Setelah semua tahapan pembuatan aplikasi telah selesai, peneliti membuat aplikasi dalam format apk (dapat dilihat pada gambar 9).

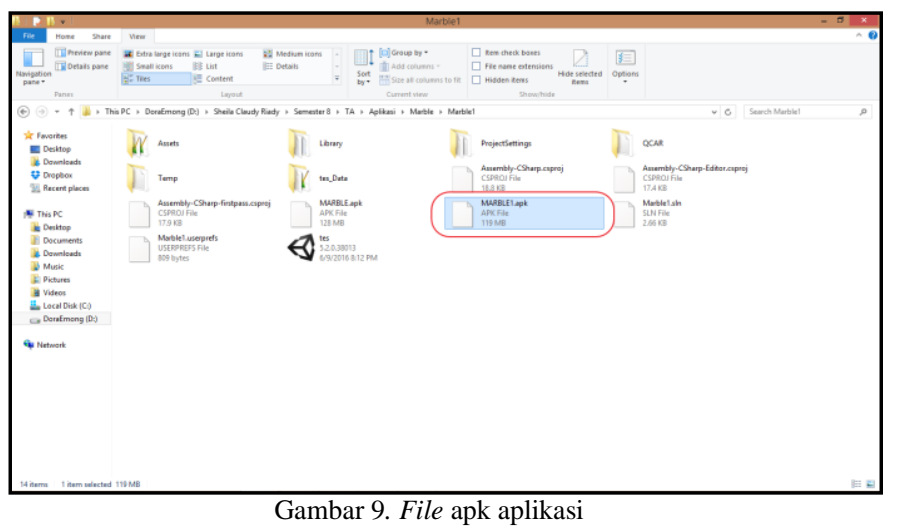

IV. HASIL DAN PEMBAHASAN

1. Tampilan icon aplikasi

Gambar 10 merupakan tampilan dari icon aplikasi Marble. Icon aplikasi ini berfungsi sebagai logo kecil penanda aplikasi. 


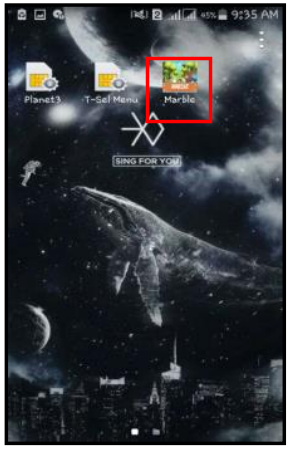

Gambar 10. Icon Aplikasi Marble

2. Tampilan Menu Utama (Main Menu). Gambar 11 merupakan tampilan awal yang akan muncul saat aplikasi dibuka oleh pengguna. Terdapat empat menu, yaitu menu AR, bantuan, tentang dan keluar.

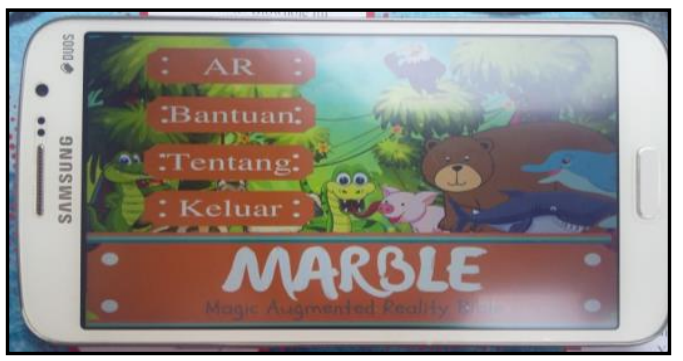

Gambar 11. Main menu Aplikasi Marble

3. Tampilan Menu AR

Gambar 12 menunjukan tampilan aplikasi saat memilih menu AR. Terdapat lima pengelompokkan hewan sesuai dengan pengelompokkan yang tertulis didalam Alkitab, yaitu hewan air, burung, binatang liar, binatang ternak dan binatang melata.

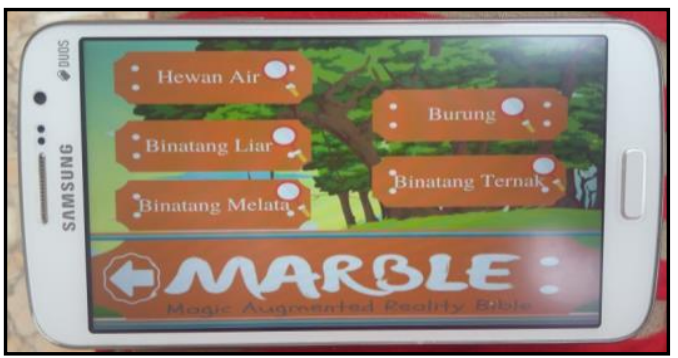

Gambar 12. Menu AR Aplikasi Marble

4. Tampilan Menu Scan Hewan

Terdapat lima jenis pengelompokkan hewan, gambar 13 merupakan salah satu contoh tampilan saat proses scan image target berlangsung.

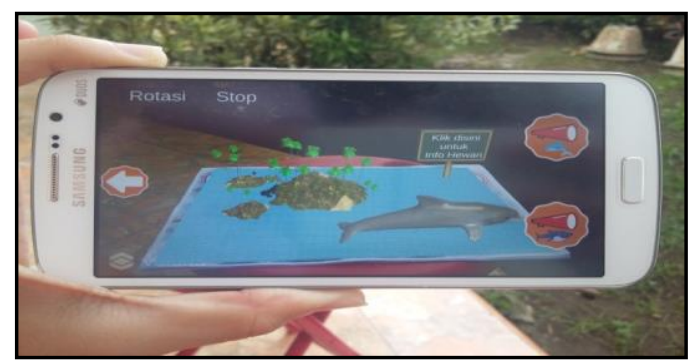

Gambar 13. Proses scan image target
Gambar 14 menunjukkan tampilan saat pengguna (user) memilih informasi hewan yang ditampilkan dalam bentuk papan informasi 3 dimensi. Slideshow aplikasi menjelaskan informasi hewan secara umum dan informasi yang berkaitan dengan hewan tersebut didalam Alkitab.

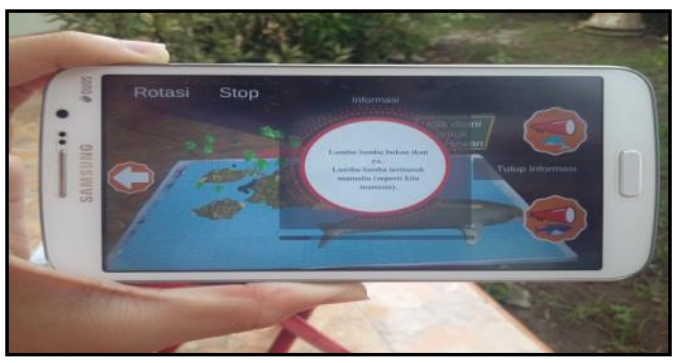

Gambar 14. Slide show informasi

5. Tampilan Menu Bantuan

Menu bantuan berisi penjelasan penggunaan aplikasi Marble. Untuk tampilan menu bantuan dapat dilihat pada gambar 15.

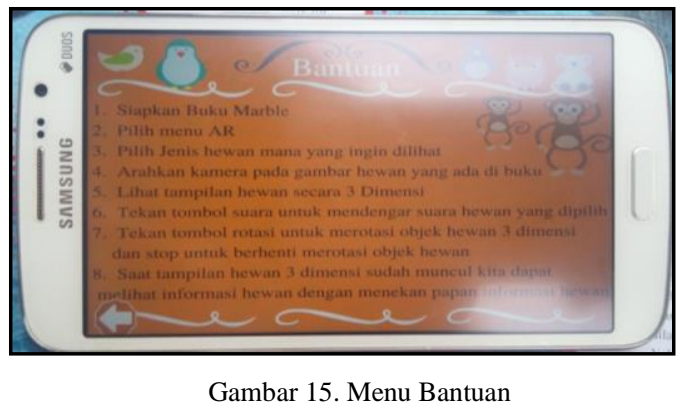

6. Tampilan Menu Tentang

Menu tentang berisi informasi aplikasi Marble seperti tujuan pembuatan aplikasi serta nama pembuat aplikasi. Dapat dilihat pada gambar 16.

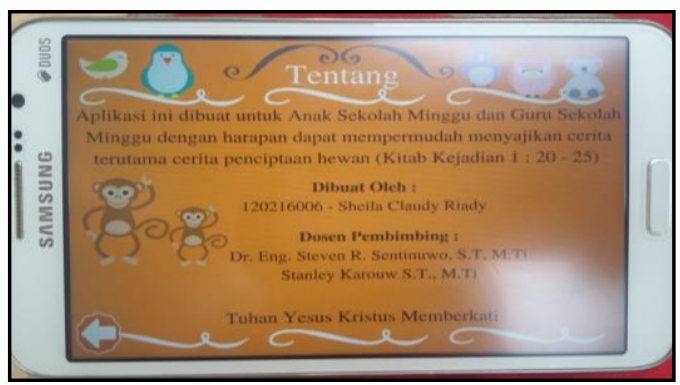

Gambar 16. Menu Tentang

\section{PENUTUP}

\section{A. Kesimpulan}

Penelitian dengan judul "Rancang Bangun Aplikasi MLearning Anak Sekolah Minggu Dengan Teknologi Augmented Reality Berbasis Android" telah berhasil dibangun dengan menggunakan teknologi markerless augmented reality.

Aplikasi Magic Augmented Reality Bible (Marble) dapat diakses melalui perangkat mobile. Aplikasi Marble ini dapat 
membantu guru-guru sekolah minggu dalam memperkenalkan hewan ciptaan Tuhan sesuai dengan pengelompokkan hewan tersebut yang tertulis dalam Alkitab serta membantu anakanak sekolah minggu dalam mengenal hewan yang telah diciptakan Tuhan.

B. Saran

1. Pengembangan selanjutnya adalah menambahkan jenis-jenis hewan serta informasi serta animasinya.

2. Pengembangan platform lebih luas seperti dapat berjalan di iOS, windows phone bahkan yang lainnya.

3. Untuk ukuran dari aplikasi diusahakan dibuat lebih kecil agar tidak membutuhkan waktu yang lama dalam menjalankan aplikasi.

\section{DAFTAR PUSTAKA}

[1] Rosyad, P. 2014. Pengenalan Hewan Augmented Reality Berbasis Android. Skripsi Program S1 Jurusan Elektro Fakultas Teknik Universitas Muhammadiyah Surakarta. Surakarta .

[2] Sutanto Leo. 2008. Kiat Sukses Mengelola \& Mengajar Sekolah Minggu. Yogyakarta: ANDI Offset.

[3] Mamangkey, J., Sinsuw, A., Robot, J., Karouw, S. 2013. Aplikasi E-Visual AID Sekolah Minggu BerbasisAndroid.http://portalgaruda.org/?ref=author\&mo $\mathrm{d}=$ profile\&id=313391. 22 Maret 2015.

[4] Warsita, Bambang M.Pd. 2008. Tekologi Pembelajaran, Landasan dan Aplikasinya. Jakarta: Rineke Cipta.

[5] Kendall, K., Kendall, J. 2010. Analisis dan Perancangan Sistem, Jakarta, PT Indeks.

\section{TENTANG PENULIS}

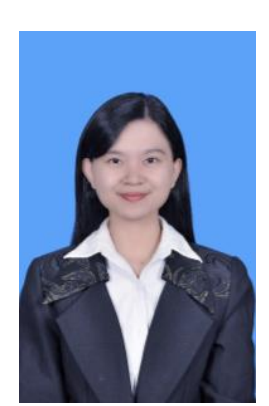

Sekilas dari penulis dengan nama Sheila Claudy Riady, anak pertama dari tiga bersaudara. Lahir di Manado, 04 Mei pada tahun 1994. Dengan latar belakang pendidikan, Sekolah Dasar (SD) Katolik Santa Theresia Malalayang, Sekolah Menengah Pertama (SMP) Katolik Santa Theresia Malalayang dan berhasil lulus pada tahun 2009. Setelah itu melanjutkan pendidikan pada tingkat Sekolah Menengah Atas (SMA) di SMA Binsus Manado dan lulus pada tahun 2012. Penulis kemudian melanjutkan studi di Fakultas Teknik, Jurusan Elektro, Program Studi Informatika, Universitas Sam Ratulangi Manado. Pada tahun 2015 bulan Agustus penulis membuat skripsi demi memenuhi syarat Sarjana (S1) dengan penelitian berjudul "Rancang Bangun Aplikasi M-Learning Anak Sekolah Minggu Dengan Teknologi Augmented Reality Berbasis Android". Pembuatan skripsi dibimbing oleh dua dosen pembimbing, yaitu Dr. Eng. Steven R. Sentinuwo,ST.,MTI dan Stanley D. S. Karouw, ST., MTI. Penulis dinyatakan lulus dari program Studi Teknik Informatika Jurusan Elektro Universitas Sam Ratulangi Manado pada tanggal 31 Oktober 2016. 